\title{
RANCANG BANGUN SISTEM INFORMASI PENJUALAN KAIN TENUN(KRE ALANG) BERBASIS WEB
}

\author{
Yana Karisma $^{1}$, Eri Sasmita Susanto ${ }^{2 *}$, Lilis Hartina ${ }^{3}$ \\ 1,2,3) Teknik Informatika, Universitas Teknologi Sumbawa \\ email: eri.sasmita.susnto@uts.ac.id*
}

\begin{abstract}
Abstrak: Kre Alang merupakan hasil kerajinan tenun berupa kain sarung berukuran lebih kecil dari sarung pada umumnya atau ukurannya setengah dari sarung biasa.Kre Alang memiliki perbedaan dengan kain tenun lainnya karena memiliki motif yang dibuat dengan benang bewarna emas.Penelitian ini bertujuan untuk meningkatkan penjualan produk kre alang dan memperluas wilayah pemasaran produk kre alang.Penelitian ini bertujuan merancang dan membangun sistem informasi penjualan berbasis web.Aplikasi ini menggunakan bahasa pemrograman PHP dengan menggunakan Mysql sebagai database.Metode pengembangan perangkat lunak menggunakan waterfall.Pengujian perangkat lunak menggunakan black box.Instrumen pengumpulan data pada penelitian mrnggunakan observasi, wawancara dan studi pustaka. Hasil akhir penelitian ini adalah Sistem Informasi Penjualan Berbasis Web di desa Sebewe yang mampu meningkatkan kebutuhan akan data dan informasi dari produk kain tenun ( kre alang), dimana calon konsumen dapat melakukan pertukaran data dan informasi secara online hingga transaksi pembelian, penjualan dan pembayaran tentang segala produk kain tenun (kre alang) dapat ditransfer melalui rekening.
\end{abstract}

Kata Kunci: Kre Alang, Rancang bangun, Sebewe, Waterfall

\begin{abstract}
Kre Alang is a weaving handicraft in the form of sarong that is smaller than a typical sarong or half the size of a regular sarong. Kre Alang is different from other woven fabrics because it has a motive made from gold colored yarn. This study aimed to increase the sales of Kre Alang products and expand the marketing area of Kre Alang products.This present research aimed to design and develop a web-based sales information system. This application used the PHP programming language by using Mysql as a database. The software development method used waterfall method. Testing software utilized black box. The data collection instruments in this study used observation, interviews, and literature study. The final result of this research is that a Web-based Sales Information System in Sebewe village is able to increase the need for data and information from woven fabric products (Kre Alang), where potential consumers can exchange data and information online to purchase, sale, and the payment transactions about woven fabric products (Kre Alang) can be made through bank account.
\end{abstract}

Keywords: Kre Alang, Design and Development, Sebewe, Waterfall

\section{PENDAHULUAN}

Kemajuan teknologi, khususnya di bidang teknologi informasi merupakan salah satu pemicu terjadinya perubahan pola pikir manusia untuk dapat memperoleh informasi secara cepat dan akurat. Teknologi informasi biasanya digunakan untuk mengolah data dan informasi termasuk menyimpan, memproses, mendapatkan, memanipulasi dan menampilkan data untuk menghasilkan informasi yang berkualitas dan terpercaya.

Seiring berkembangnya penggunaan teknologi internet dan teknologi menyebabkan munculnya teknologi E-commerce yang berbasis teknologi internet.E-Commerce atau perdagangan elektronik adalah penggunaan jaringan komunikasi dankomputer untuk melaksanakan proses bisnis (McLeod, 2008 : 59).

Salah satu bisnis yang menjaditerkenal di masyarakat sekarang ini adalah dalam bidang belanja online sehingga memunculkan bentuk model toko-toko virtual, salah satu bentuk usaha dari pebisnis online adalah memberikan fasilitas dan pelayanan yang memuaskan terhadap pelanggan.

Desa Sebewe merupakan salah satu desa penghasil kain tenun (Kre Alang) di kabupaten Sumbawa yang beralamat dijalan undru no 2 lintas desa Sebewe kecamatan Moyo Utara.Kre Alang merupakan hasil kerajinan tenun berupa kain sarung berukuran lebih kecil dari sarung pada umumnya atau ukurannya setengah dari sarung biasa.Kre Alang memiliki perbedaan dengan kain tenun lainnya karena memiliki motif yang dibuat dengan benang bewarna emas.Proses pembuatannya memakan waktu yang lumayan lama, untuk satu Kre Alang bisa sampai satu bulan tergantung dari motif yang dibuat sehingga untuk satu buah Kre Alang di jual dengan harga jutaan rupiah.

Akan tetapi saat ini sistem penjualan kain tenun (Kre Alang) ini masih secara manual, seperti promosi barang masih mengandalkan banner dan tidak ada 
penjualan jarak jauh yang bisa mempermudah produsen dalam memperluas wilayah pemasaran. Selain itu, konsumen juga harus datang sendiri ke lokasi dan pembayaran dilakukan secaara tunai, hal ini tentu meyulitkan konsumen dikarenakan harus datang sendiri ke lokasi dan mengeluarkan biaya untuk mendatangi lokasi produksi kain tenun (Kre Alang).

Menyikapi permasalahan tersebut dibutuhkan Sistem Informasi Penjualan Berbasis Web yang mampu meningkatkan kebutuhan akan data dan informasi dari produk kain tenun (Kre Alang), dimana calon konsumen dapat melakukan pertukaran data dan informasi secara online hingga transaksi pembelian, penjualan dan pembayaran tentang segala produk kain tenun (Kre Alang) dapat ditransfer melalui rekening.

\section{METODOLOGI PENELITIAN}

Metode pengembangan perangkat lunak yang digunakan dalam penelitian ini adalah metode pengembangan perangkat lunak Waterfall yang terdiri dari lima tahap yaitu :

1. Analisa Kebutuhan

Analisa kebutuhan ini merupakan tahap awal yang dilakukan oleh peneliti dalam mengembangkan sistem.Dalam analisa ini harus mendapatkan beberapa hal yang dianggap menunjang penelitian yang dilakukan, kebutuhan pengguna atau user, perangkat keras, perangkat lunak dan pengguna data. Dengan menggunakan analisa kebutuhan sistem maka dapat diketahui kebutuhan apa saja yang diperlukan dalam membangun sistem informasi kain tenun. Hasil analisa didapatkan dari pengumpulan data yang dilakukan terlebih dahulu yaitu dengan cara wawancara dan studi pustaka.

2. Desain Sistem

Setelah melakukan pengumpulan data dan mengetahui definisi aplikasi yang akan dikembangkan, maka selanjutnya adalah melakukan perancangan aplikasi yang akan dibangun. Perancangan ini meliputi perancangan sistem aplikasi, perancangan basis aplikasi data dan perancangan tampilan aplikasi.

3. Penulisan Kode Program

Tahap ini merupakan proses puncak dalam pembuatan aplikasi, yaitu merupakan proses penciptaan sebuah sistem informasi yang berkesesuaian dengan apa yang telah dilakukan pada tahap perencanaan, analisa dan desain sistem. Penulis selanjutnya akan melakukan penulisan kode program dengan menggunakan bahasa pemrogramman PHP.
4. Pengujian Program

Tahap ini adalah tahap pengujian dan tahap pendukung yang artinya aplikasi yang telah dibuat dari hasil analisis masalah yang telah melalui tahaptahap desain, penulisan kode program barulah masuk kedalam pengujian program, sehingga akan dapat diketahui seperti apa hasil kinerja aplikasi tersebut, kemudian dapat diketahui pula apakah aplikasi yang telah dibuat bejalan dengan baik sesuai dengan apa yang diharapkan. Pada langkah pengujian program ini, penulis akan melakuakan pengujian dengan menggunakan metode pengujian black box dimana pengujian dilakukan pada persyaratan fungsional perangkat lunak.

\section{Penerapan Program}

Pada proses ini penulis melakukan pengoperasian aplikasi yang telah selesai dibuat pada UKM Gali Sebangsa untuk mengganti sistem yang sebelumnya menggunakan caramanual dengan menggunakan buku, sekarang UKM Gali Sebangsa menggunakan sistem komputasi yang membantu pengelolaan data penjualan.

\section{HASIL DAN PEMBAHASAN}

Dengan menggunakan metode pengembangan perangkat lunak Waterfall dalam penelitian ini, maka proses yang dilakukan dalam membangun Sistem Informasi Penjualan Kain Tenun(Kre Alang) Berbasis Web Di Desa Sebewe adalah sebagai berikut :

\section{Analisis Kebutuhan}

Merupakan tahap awal untuk mendapatkan data dan informasi yang dibutuhkan.Teknik pengumpulan data merupakan langkah yang paling strategis dalam penelitian, karena tujuan utama dari penelitian adalah mendapatkan data. Dimana pada tahap ini peneliti melakukan wawancara langsung dengan pihak UKM Gali Sebangsa untuk mendapatkan informasi terkait dengan data-data yang dibutuhkan untuk membangun Sistem Informasi Penjualan Kain Tenun(Kre Alang) Berbasis Web Di Desa Sebewe. Berikut adalah hasil analisis kebutuhan :

a. Kebutuhan Pengguna atau User

Adapun kebutuhan pengguna atau user dalam sistem informasi penjualan ini adalah:

- User membuka halaman home terlebih dahulu

- Pengguna atau user dapat melihat daftar produk, spesifikasi produk, harga produk dan produk yang dijual.

- Pengguna atau user harus melakukan registrasi terlebih dahulu, kemudian login. 
b. Kebutuhan Perangkat Keras

Kebutuhan minimum perangkat keras untuk pembuatan sistem informasi penjualan Kain Tenun(Kre Alang) Berbasis Web Di Desa Sebewe adalah sebagai berikut :

- $\quad$ Prosessor Intel Pentium 4

- RAM 512 MB

- Harddisk 80 GB

- LCD beresolusi 1024x768 pixels, Mouse, Keyboard

c. Kebutuhan Perangkat Lunak

Kebutuhan perangkat lunak untuk pembuatan sistem informasi penjualan Kain Tenun(Kre Alang) Berbasis Web Di Desa Sebewe adalah sebagai berikut :

- Windows $732 / 64$ bit

- $\quad$ Xampp Version 3.2.2

- MySQL Version 5.6.20

- $\quad$ PHP Version 5.5.15

- $\quad$ Apache Version 2.4.10

- $\quad$ phpMyAdmin Version 4.2.7.1

- $\quad$ Notepad++ version 7.2.2

2. Desain Sistem

Dalam proses perancangan sistem, di mana bertujuan untuk memberikan gambaran tentang sistem yang akan di bangun dan tampilan dari sistem. Tahap membantu peneliti dalam mendefinisikan arsitektur sistem secara keseluruhan.

\section{Diagram Konteks}

Diagram Konteks ini merupakan penggambaran secara garis besar Sistem Informasi Penjualan Kain Tenun yang dibuat untuk mengetahui hubungan langsung antara user dengan sistem. Diagram konteks ini merupakan level tertinggi dari DFD (Data Flow Diagram) yang menggambarkan seluruh input ke sistem atau output dari sistem. Dibawah ini merupakan Diagram Konteks Sistem Informasi Penjualan Kain Tenun(Kre Alang) Berbasis Web Di Desa Sebewe.

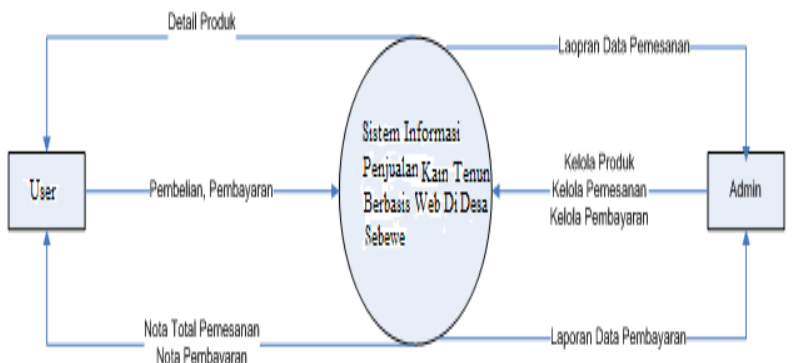

Gambar 1. Diagram Konteks

\section{Data Flow Diagram (DFD)}

DataFlow Diagram merupakan tahapan perancangan aplikasi yang aliran informasi dan transformasi informasi yang diaplikasikan sebagai data yang mengalir dari masukan (input) dan keluaran (output). Penggambaran DFD menyatakan dari mana datangnya informasi dan dikirim kemana informasi tersebut dibutuhkan untuk disimpan dan diakses.

Berikut adalah DataFlow Diagram level 0 Rancang Bangun Sistem Informasi PenjualanKain Tenun (Kre Alang) Berbasis Web Di Desa Sebewe yang menggambarkan semua alur kerja dari sistem yang akan dibangun.

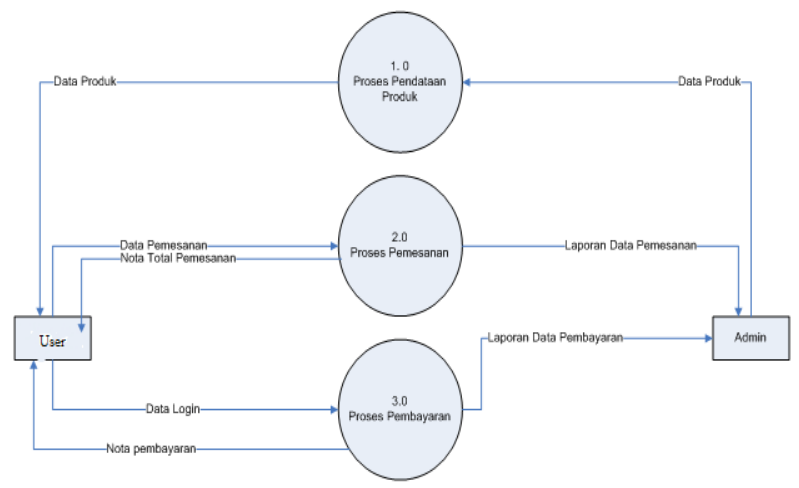

Gambar 2. DFD Level 0

\section{Entity Relationship Diagram (ERD)}

Entity Relationship Diagram (ERD) merupakan bentuk paling awal dalam melakukan perancangan basis data relasional. ERD digunankan untuk melihat hubungan antara entitas yang terdapat dalam Sistem Informasi Pengelolahan Data Nasabah.Berikut adalah ERD yang terdapat dalam Sistem Informasi Penjualan Kain Tenun.

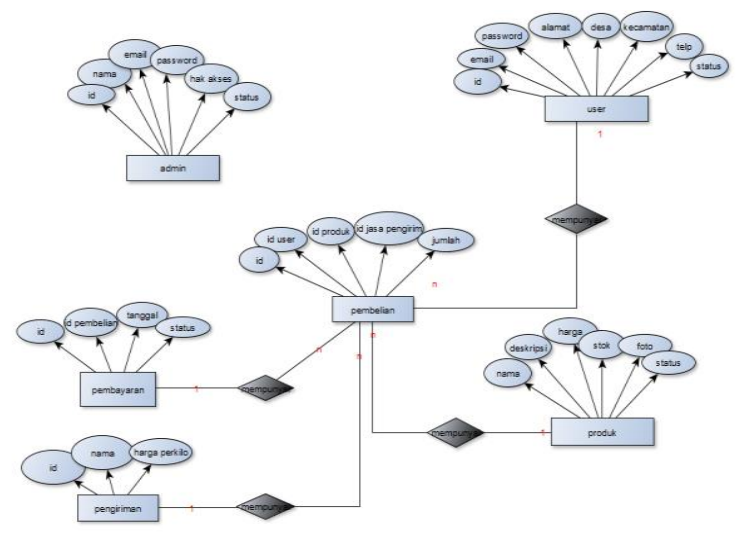

Gambar 3. Entity Relationship Diagram 


\section{Rancangan Struktur Database}

Dalam perancangan struktur database Sistem Informasi Penjualan Kain Tenun dibutuhkan beberapa tabel yaitu tabel admin, user, produk, pembelian, pembayaran dan jasa pengiriman.

a. Tabel Admin

Nama tabel :admin

Keterangan : Tabel admin digunakan untuk menyimpan data petugas ( $a d m i n)$ yang mengelola sistem.

Berikut struktur tabel admin.

\begin{tabular}{|c|c|c|c|c|}
\hline \multicolumn{5}{|c|}{ Tabel 1.Admin } \\
\hline No & Field & Type & Length & Extra \\
\hline 1 & Id Admin & Int & 11 & $\begin{array}{c}\text { Primary } \\
\text { key }\end{array}$ \\
\hline 2 & Nama & Varchar & 50 & \\
\hline 3 & Email & Varchar & 50 & \\
\hline 4 & Password & Varchar & 50 & \\
\hline 5 & Hak_akses & Int & 11 & \\
\hline 6 & Status & Int & 11 & \\
\hline
\end{tabular}

b. Tabel User

Nama tabel :user

Keterangan : Tabel user ini digunakan untuk menyimpan data user.

Berikut struktur tabel user.

\begin{tabular}{|c|c|c|c|c|}
\hline No & Field & Type & Length & Extra \\
\hline 1 & Id User & Int & 11 & $\begin{array}{c}\text { primary } \\
\text { key }\end{array}$ \\
\hline 2 & Email & Varchar & 50 & \\
\hline 3 & Password & Varchar & 50 & \\
\hline 4 & Alamat & Text & 50 & \\
\hline 5 & Desa & Varchar & 50 & \\
\hline 6 & Kecamatan & Varchar & 50 & \\
\hline 7 & Telp & Int & 50 & \\
\hline 8 & Status & Int & 11 & \\
\hline
\end{tabular}

c. Tabel Produk

Nama tabel : produk

Keterangan : Tabel produk ini digunakan untuk menyimpan data produk.

Berikut struktur tabel produk.
Tabel 3. Produk

\begin{tabular}{|c|c|c|c|c|}
\hline No & Field & Type & Length & Extra \\
\hline 1 & Id Produk & Int & 11 & $\begin{array}{c}\text { Primary } \\
\text { key }\end{array}$ \\
\hline 2 & Nama & Varchar & 100 & \\
\hline 3 & Deskripsi & Varchar & 50 & \\
\hline 4 & Harga_jual & Int & 11 & \\
\hline 5 & Satuan & Varchar & 10 & \\
\hline 6 & Berat & Varchar & 50 & \\
\hline 7 & Stok & Int & 11 & \\
\hline 8 & Foto & Varchar & 200 & \\
\hline 9 & Status & Int & 11 & \\
\hline
\end{tabular}

d. Tabel Pembelian

Nama tabel : pembelian

Keterangan : Tabel pembelian digunakan untuk menyimpan data pembelian.Berikut struktur tabel nasabah.

Tabel 4. Pembelian

\begin{tabular}{|c|c|c|c|}
\hline \multicolumn{5}{|c}{ Tabel 4. Pembelian } \\
\hline Field & Type & Length & Extra \\
\hline Id Pembelian & Int & 11 & Primary key \\
\hline Id User & Int & 11 & \\
\hline Id Produk & Int & 11 & \\
\hline Jumlah & Int & 11 & \\
\hline Status & Int & 11 & \\
\hline
\end{tabular}

e. Tabel Pembayaran

Nama tabel : pembayaran

Keterangan : Tabel pembayaran digunakan untuk menyimpan data pembayaran. Berikut struktur tabel pembayaran.

Tabel 5. Pembayaran

\begin{tabular}{|c|c|c|c|}
\hline Field & Type & Length & Extra \\
\hline Id Pembayaran & Int & 11 & $\begin{array}{c}\text { Primary } \\
\text { key }\end{array}$ \\
\hline Id Pembelian & Int & 11 & \\
\hline $\begin{array}{c}\text { Id Jasa } \\
\text { Pengirim }\end{array}$ & Int & 11 & \\
\hline Berat & Int & 11 & \\
\hline Id_user & Int & 11 & \\
\hline Tanggal & Date & & \\
\hline Bukti_bayar & Varchar & 450 & \\
\hline Tanggal_bayar & Date & & \\
\hline Status & Int & 11 & \\
\hline
\end{tabular}


f. Tabel Pengiriman

Nama table : pengiriman

Ketarangan : Tabel pengiriman digunakan untuk menyimpan data pengiriman.

Berikut struktur table pengiriman.

Tabel 6. Pengiriman

\begin{tabular}{|c|c|c|c|}
\hline Field & Type & Length & Extra \\
\hline $\begin{array}{c}\text { Id } \\
\text { Pengiriman }\end{array}$ & Int & 11 & Primary key \\
\hline Nama & Varchar & 50 & \\
\hline $\begin{array}{c}\text { Harga } \\
\text { Perkilo }\end{array}$ & Int & 50 & \\
\hline
\end{tabular}

\section{Perancangan Antar Muka (User Interface)}

Rancangan user interface merupakan rancangan tampilan antarmuka dari sistem yang akan dibangun. Berikut merupakan rancangan user interface dari Sistem Informasi Penjualan Kain Tenun.

a. Rancangan Tampilan Login Admin

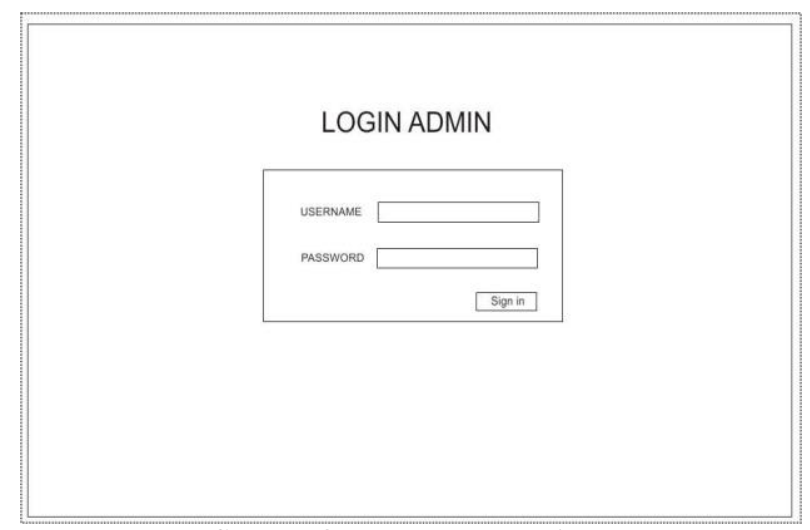

Gambar 4. Rancangan Tampilan

Login Admin

Rancangan tampilan login admin merupakan rancangan tampilan awal dari sistem ketika sistem pertama kali dijalankan. Pada rancangan ini terdapat dua form yaitu username dan password dimana petugas (admin) harus mengisi dengan benar jika ingin masuk kedalam sistem untuk mengelolah data.

b. Rancangan Tampilan Dashboard

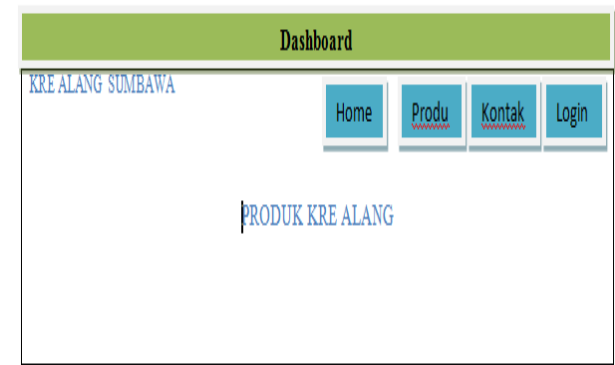

Gambar 5. Rancangan Tampilan Dashboard

Rancangan tampilan dashboard ini merupakan halaman yang muncul ketika admin melakukan login dengan benar. Pada halaman ini menampilkan beberapa menu-menu utama dari sistem untuk mengakses dan mengelola data penjualan.

3. Penulisan Kode Program

Dalam tahapan ini desain-desain dari perancangan sistem yang akan di bangun mulai di implementasikan ke dalam bahasa pemrograman. Proses implementasi di mulai dari pembangunan database pada basis data MySQL dengan menggunakan XAMPP. Kemudian proses pengkodean dibantu dengan bahasa pemrograman PHP (Hypertext Preprocessor) menggunakan frameworkCodeIgniter dan web editor menggunakan aplikasi Notepad++.

4. Pengujian Program

Implementasi Program adalah tahap pengujian program yang telah dibangun sesuai dengan perancangan sistem sebelumnya yaitu untuk mencari kesalahan penulisan kode program. Adapun implementasi Sistem Informasi Pengelolahan Data Nasabah Bank Sampah adalah sebagai berikut :

\section{a. Halaman Login Admin}

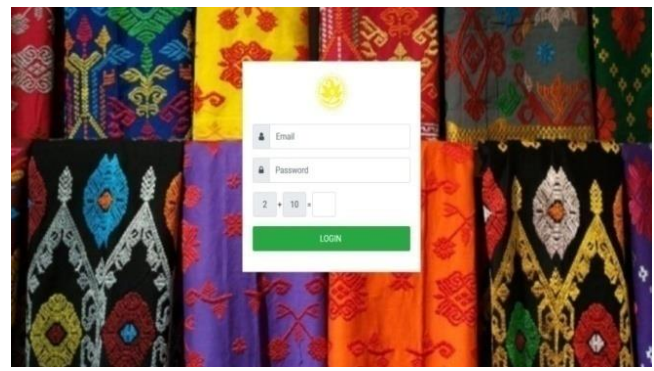

Gambar 6. Halaman Login Admin

Halaman Login adalah halaman yang pertama kali tampil ketika sistem pertama kali dibuka. Halaman ini terdapat dua form inputan yaitu emailsamapassword. Untuk bisa masuk kedalam sistem, petugas (admin) harus mengisi form email 
dan password dengan benar sehingga Petugas (admin) dapat mengelolah data-data penjualan kain tenun.

\section{b. Halaman Dashboard}

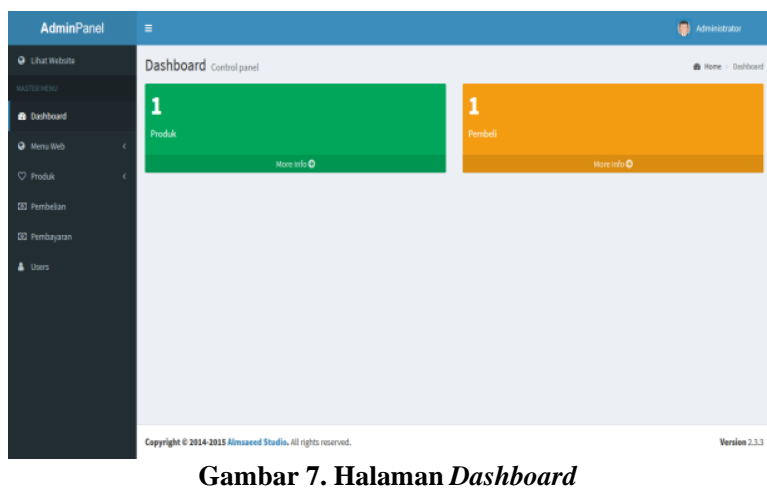

Ketika petugas (admin) melakukan login dengan benar, maka tampilan yang pertama masuk yaitu tampilan Dashboard.Pada halaman ini petugas (admin) bisa mengakses menu-menu utama yang digunakanan untuk memanggil form-form seperti Data produk, Data pembelian, Tabungan pembayaran dan data user.

c. Halaman Data Produk

Halaman data produk digunakan untuk menampilkan data-data produk seperti nama pproduk, harga produk dan deskripsi produk. Pada halaman ini juga terdapat form tambah keranjag dan pesan whatsapp.

\section{d. Halaman User}

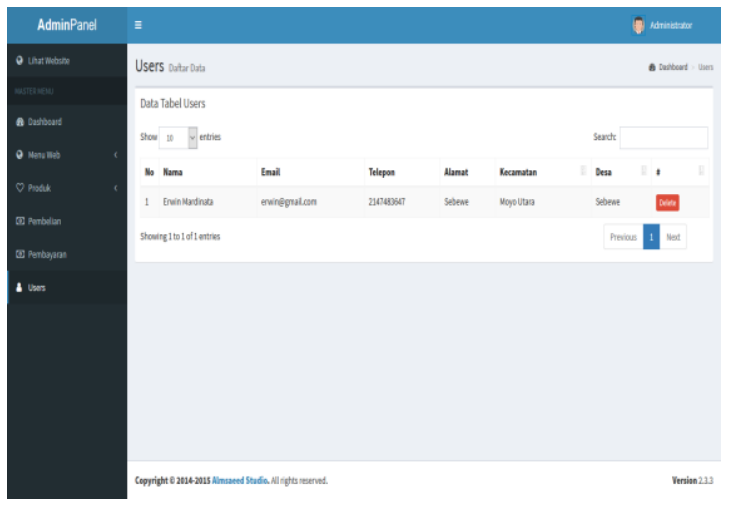

Gambar 8. Halaman User

Halaman User digunakan petugas (admin) untuk menampilkan data-data user dalam bentuk tabel dari nama, email, telepon, alamat, kecamatan dan desa. Pada halaman ini juga terdapat form search untuk melakukan pencarian terhadap data user dan delete untuk menghapus data user.

\section{KESIMPULAN DAN SARAN}

\section{Kesimpulan}

Dari hasil analisis dan perancangan sistem yang telah dilakukan sebelumnya, maka penulis dapat mengambil kesimpulan bahwa Rancang Bangun Sistem Informasi Penjualan Kain Tenun (Kre Alang) Berbasis Web Di Desa Sebewe telah selesai dibangun menggunakan bahasa pemrogramman $P H P$ dengan frameworkCodeIgniter, database MySql dan metode waterfall sebagai metode pengembangan perangkat lunak yang dapat digunakan oleh UKM Gali Sebangsa Desa Sebewe untuk mempermudah dan mempercepat petugas (admin) mengelolah penjualan produk kain tenun.

\section{Saran}

Dari hasil pembuatan Rancang Bangun Sistem Informasi Penjualan Kain Tenun (Kre Alang) Berbasis Web Di Desa Sebewe, penulis memberikan saran agar pada tahap selanjutnya dilakukan pengembangan sistem diantara lain meliputi :

1. Penambahan modul penjualan kain tenun ke pengelolah terakhir kain tenun agar jumlah pemasukkan kain tenun secara otomatis dijumlahkan oleh komputer.

2. Aplikasi ini agar bisa di kembangkan ke versi Mobile (Android IOS).

3. Desain tampilan aplikasi ini agar bisa diperbagus lagi

4. Untuk pengembangan selanjutnya semoga aplikasi ini bisa terkoneksi dan terintegrasi dengan aplikasi seperti, aplikasi Buka Lapak. aplikasiShopee, Lazada dan aplikasi lainnya.

\section{DAFTAR PUSTAKA}

[1]Anhar. 2010. Panduan Menguasai Php dan My SQL Secara Otodidak. Jakarta : Transmedia.

[2]Arbani, Marizka. (2011). "Pengembangan Sistem Informasi Sekolah Berbasis Web". Skripsi.Program Studi Muamalat (Ekonomi Islam) Universitas Islam Negeri Syarif Hidayatullah. Jakarta.

[3]Daqiqil, Ibnu. 2011. Framework CodeIgniter Sebuah Panduan Dan Best Practice. Pekanbaru: Andi.

[4]Pratama\& Sugiarti (2014) “ Rancang Bangun Pengembangan Sistem Jejaring Sosial Berbasis Mobile Web Menggunakan Framework Fusebox Pada PT.Mantenboshi Creative Indonesia". Jurnal Sistem Informasi, Vol. 7 No. 1.hlm 2. 
[5]Fatta, Al Hanif, 2009. Rekayasa Sistem Pengenalan Wajah. Yogyakarta: CV ANDI OFFSET.

[6]M. Sidi Mustaqbal, Roeri Fajri Firdaus \& Hendra Rahmadi (2015) “ Pengujian Aplikasi Menggunakan Black Box Testing Boundary Value Analysis “. Jurnal Ilmiah Teknologi Informasi Terapan, Vol 1, No 3, hlm.33-34.

[7]Nugroho, Prasetyo E. 2009. Rekayasa Perangkat Lunak. Bandung : Politeknik Telkom.

[8] Shabur Miftah Maulana, Heru Susilo \& Riyadi (2015) “ Implementasi E-Commerce Sebagai Media Penjualan Online". Jurnal Adminitrasi Bisnis, Vol. 7 No. 1.hlm 2.

[9]Solichin, Achmad.2010. My SQL 5 Dari Pemula Hingga Mahir. Jakarta: Universitas Budi Luhur.

[10]Soeherman, Bonnie. 2008.Designing Information System. Jakarta:PT Elex Media Komputindo.

[11]Simarmata, Janner. 2010. Rekayasa Perangkat Lunak. Yogyakarta: CV ANDI OFFSET.

[12]Tata Sutabri. 2012. Analisis Sistem Informasi.

Andi. Yogyakarta

[13]Yudhanto, Yudha. 2019. Mudah Menguasai Framework Laravel. Jakarta: PT Elex Media Komputindo.

[14]Yuhefizar. 2008. Cara Mudah Membangun Website Intraktif Menggunakan Content Management System. Jakarta: Granmedia.

[15]Yuanda, Prasetya I. 2016. Sistem Informasi Penjualan Barang Di Toko The Secret Home Surabaya Berbasis Web (Studi Kasus Barang Fashion Wanita). Surabaya: Perpustakaan Universitas Airlangga. 